\title{
Expression of the $h t r B$ gene is essential for responsiveness of Salmonella typhimurium and Campylobacter jejuni to harsh environments
}

\begin{abstract}
Correspondence
Benjamin N. Fry

ben.fry@rmit.edu.au
\end{abstract}

Received 19 June 2006

Revised 5 September 2006

Accepted 18 September 2006

\author{
Vongsavanh Phongsisay, Viraj N. Perera and Benjamin N. Fry
}

School of Applied Sciences, Royal Melbourne Institute of Technology University, Bundoora, Melbourne, Victoria 3083, Australia

\begin{abstract}
In Campylobacter jejuni, an htrB homologous gene is located in the lipo-oligosaccharide synthesis gene cluster. This study examined the effects of $h t r B$ expression on the responsiveness of Salmonella typhimurium and C. jejuni to harsh environments. Complementation experiments showed that the C. jejuni htrB gene could restore the normal morphology of the Salmonella $h$ trB mutant, and its ability to grow without inhibition under heat, acid and osmotic stresses, but not bile stress. This indicated that the htrB genes in C. jejuni and S. typhimurium exhibit similar pleiotropic effects. Moreover, quantitative real-time RT-PCR showed that expression of the C. jejuni $h t r B$ gene was upregulated under acid, heat, oxidative and osmotic stresses, but did not change under bile stress. This indicated that the $C$. jejuni htrB gene plays a role in regulating cell responses to various environmental changes. Furthermore, deletion mutation of the $h t r B$ gene in $C$. jejuni was lethal, indicating that the $h t r B$ gene is essential for $C$. jejuni survival. Therefore, these results showed that expression of the $h t r B$ gene is essential for the response of $S$. typhimurium and C. jejuni to environmental stresses.
\end{abstract}

\section{INTRODUCTION}

Modulation of lipid A acylation in Gram-negative bacteria results in pleiotropic effects. In Escherichia coli, mutation of the $h \operatorname{trB}$ gene encoding a lipid A acyltransferase leads to inhibition of bacterial growth at high temperature (Karow \& Georgopoulos, 1991; Karow et al., 1991), morphological change from short to filamentous rods (Karow et al., 1991), and unusually increased bile resistance (Karow \& Georgopoulos, 1992). In Salmonella typhimurium, inactivation of the $h t r B$ homologous gene exhibits not only the same effects as those seen in E. coli, but also hyperflagellation and severely limited virulence (Jones et al., 1997; Sunshine et al., 1997). In Haemophilus influenzae, knockout of the htrB gene results in increased bile sensitivity (Lee et al., 1995), increased sensitivity to human antimicrobial peptides $(\beta$ defensins) (Starner et al., 2002), decreased colonization capacity (Swords et al., 2002), decreased intracellular viability (Swords et al., 2002), and decreased pro-inflammatory cytokine induction (Tong et al., 2001), but it does not affect morphology (Lee et al., 1995).

Campylobacter jejuni is an enteric bacterium causing human gastroenteritis worldwide (Coker et al., 2002; O'Ryan et al., 2005). The predominant symptoms are inflammatory diarrhoea, abdominal pain, and/or fever. Poultry products,

Abbreviations: $\mathrm{C}_{\mathrm{T}}$, cycle threshold; DOC, sodium deoxycholate; $\mathrm{Km}$, kanamycin resistance cassette; LOS, lipo-oligosaccharide. milk and water are frequently reported as the infectious sources. Infections are mainly observed in children under 5 years of age, and cause serious complications in immunocompromised hosts (Monselise et al., 2004; Ramon Maestre et al., 2001).

The lipo-oligosaccharide (LOS) of C. jejuni is a major surface molecule consisting of two parts, the core oligosaccharide and lipid A. The core region is involved in virulence (Fry et al., 2000) and induction of GuillainBarré syndrome, an autoimmune neuropathy of the peripheral nervous system (Yuki et al., 2004). The lipid A of the LOS molecule possesses endotoxic properties (Naess \& Hofstad, 1984). This crucial molecule is partly encoded by the wlaII gene cluster, which shows a high degree of variation among strains (Gilbert et al., 2002; Parker et al., 2005). In C. jejuni strain HB 93-13, it contains 13 consecutive genes: waaC, htrB, wlaNC, wlaND, cgtA, cgtB, cstII, neuB, neuC, neuA, wlaVA, wlaQA and waaF (GenBank accession no. AY297047). The htrB homologue found in this wlaII gene cluster is conserved in C. jejuni, and is similar to the htrB gene of S. typhimurium, E. coli and H. influenzae. Functionally, the $C$. jejuni htrB gene encodes a putative acyltransferase involved in lipid A synthesis (Gilbert et al., 2000, 2002; Parkhill et al., 2000). This study examined the effects of $h t r B$ expression on the responsiveness of $S$. typhimurium and C. jejuni to harsh environments, using complementation, gene expression and mutation experiments. 


\section{METHODS}

Bacterial strains and growth conditions. C. jejuni strains $\mathrm{HB}$ 93-13 (Ho et al., 1995), O:4, O:41, O:36, 81116 (Palmer et al., 1983), NCTC 11168, ATCC 43446 and OH 4382 (Aspinall et al., 1994) were included in this study. C. jejuni was grown on Columbia agar plates supplemented with $5 \%(\mathrm{v} / \mathrm{v})$ defribinated horse blood under microaerobic conditions $\left(5 \% \mathrm{O}_{2}, 10 \% \mathrm{CO}_{2}, 85 \% \mathrm{~N}_{2}\right)$ at $42{ }^{\circ} \mathrm{C}$ for $16 \mathrm{~h}$, unless otherwise stated. E. coli $\mathrm{DH} 5 \alpha$ was grown in Luria-Bertani (LB) broth or agar at $37^{\circ} \mathrm{C}$ for $16 \mathrm{~h}$. S. typhimurium strains SL1344 (wild-type) and SL1344 htrB1:: Tn10 (htrB mutant, tetracycline resistance) were kindly provided by Dr B. D. Jones, Department of Microbiology, University of Iowa (Jones et al., 1997; Sunshine et al., 1997). S. typhimurium was grown in LB broth or on $\mathrm{LB}$ agar at $30^{\circ} \mathrm{C}$ for $16 \mathrm{~h}$, unless otherwise stated. Media were supplemented with $150 \mu \mathrm{g}$ ampicillin $\mathrm{ml}^{-1}, 15$ or $50 \mu \mathrm{g}$ kanamycin $\mathrm{ml}^{-1}, 20 \mu \mathrm{g}$ tetracycline $\mathrm{ml}^{-1}, 2 \%(\mathrm{w} / \mathrm{v}) \mathrm{X}$-Gal in dimethyl formamide $(40 \mu \mathrm{l}$ for each LB plate), and $100 \mathrm{mM}$ IPTG (40 $\mu$ l for each LB plate), when appropriate.

Analysis of DNA and amino acid sequences. Clone manager version 6 (Scientific and Education Software) was used to design primers, plan cloning and analyse DNA and amino acid sequences. Primers were designed using the wlaII-LOS synthesis gene cluster of C. jejuni strain HB 93-13 (GenBank accession no. AY297047), unless otherwise stated.

DNA manipulation. Plasmid DNA was isolated using the mini-prep procedure described by Ausubel et al. (1995), and/or the QIAprep Spin Miniprep kit (Qiagen) according to the manufacturer's instructions. The DNA quantity was determined using spectrophotometry. Restriction enzymes, T4 DNA ligase and alkaline phosphatase were purchased from Promega, and used according to the manufacturer's instructions. Restriction mapping was performed to confirm the composition and size of the constructed plasmids by digestion with appropriate restriction enzymes. Transformation of $C$. jejuni with plasmid or genomic DNA was performed using electroporation ( $25 \mu \mathrm{F}, 1.25 \mathrm{kV}$ and $600 \Omega$, gene pulser apparatus; Bio-Rad) and/or natural transformation (biphasic technique), as described by Wassenaar et al. (1993). Transformation of E. coli and S. typhimurium with plasmid DNA was performed using electroporation $(25 \mu \mathrm{F}$, $2.48 \mathrm{kV}$ and $200 \Omega$, gene pulser apparatus; Bio-Rad). Competent cells for E. coli and S. typhimurium were prepared in cold $10 \%(\mathrm{v} / \mathrm{v}) \mathrm{gly}-$ cerol as described by Sambrook \& Russell (2000).

pfu-PCR. $p f u$-PCR was used to amplify a DNA fragment from purified chromosomal DNA. The reaction mixture was prepared in a $50 \mu \mathrm{l}$ total volume of $1 \times p f u$ buffer containing $200 \mu \mathrm{M}$ each of dATP, dTTP, dCTP and dGTP, $100 \mathrm{ng}$ of each primer, $100 \mathrm{ng}$ DNA, and $5 \mathrm{U} p f u$ polymerase (Roche). The PCR conditions were as follows: $94^{\circ} \mathrm{C}$ for $3 \mathrm{~min}$ (initial denaturation); 35 cycles of $94^{\circ} \mathrm{C}$ for $30 \mathrm{~s}$ (denaturation), $50{ }^{\circ} \mathrm{C}$ for $1 \mathrm{~min}$ (annealing), $72{ }^{\circ} \mathrm{C}$ for $x$ min (extension); and $72{ }^{\circ} \mathrm{C}$ for $7 \mathrm{~min}$ (final elongation). $x$ was calculated by dividing the length of the PCR product by $500 \mathrm{bp}$, as $p f u$ polymerase synthesizes $500 \mathrm{bp} \mathrm{min}^{-1}$.

Colony-PCR. Colony-PCR was used to screen transformants carrying new constructs. The reaction mixture was prepared in a $50 \mu \mathrm{l}$ total volume of $1 \times \mathrm{Taq}$ buffer containing $1.5 \mathrm{mM} \mathrm{MgCl} 2,200 \mu \mathrm{M}$ each of dATP, dTTP, dCTP and dGTP, $100 \mathrm{ng}$ of each primer, and $2.5 \mathrm{U}$ Taq polymerase (ABI). A $200 \mu$ (maximum volume) tip was used to gently touch a colony on a culture plate, and the colony material was directly mixed into a PCR tube containing master reagent, which had been prepared beforehand. The PCR conditions were as follows: $94{ }^{\circ} \mathrm{C}$ for $10 \mathrm{~min} ; 35$ cycles of $94{ }^{\circ} \mathrm{C}$ for $30 \mathrm{~s}, 50{ }^{\circ} \mathrm{C}$ for $1 \mathrm{~min}, 72{ }^{\circ} \mathrm{C}$ for $y \mathrm{~min}$; and $72{ }^{\circ} \mathrm{C}$ for $7 \mathrm{~min}$. $y$ was calculated by dividing the length of the PCR product by $1000 \mathrm{bp}$, as Taq polymerase synthesizes $1000 \mathrm{bp} \mathrm{min}^{-1}$.
Construction of a plasmid carrying the C. jejuni htrB gene in the S. typhimurium htrB mutant. A 917 bp DNA fragment containing $18 \mathrm{bp}$ of the waaC gene (upstream adjacent gene), the entire $h t r B$ gene ( $888 \mathrm{bp}$ ) and $11 \mathrm{bp}$ of the wlaNC gene (downstream adjacent gene) of $C$. jejuni strain HB 93-13 was amplified by $p f u$-PCR with primers BamHI-waaC-F (5'-TTGCCAAAGGATCCCTTAATGAAAAATAGTGATAG- $3^{\prime}$ ) and ClaI-wlaNC-R (5'-TTGTTATCGATTCATTTTGCACCCTTGT- $3^{\prime}$ ). A PCR product was cloned into the pBluescript plasmid in the same orientation as the ampicillin-resistance cassette, using the BamHI and ClaI sites, and the resultant construct was subsequently introduced into $E$. coli $\mathrm{DH} 5 \alpha$ by electroporation. Transformants carrying the $h t r B$ gene constructs were screened using colony-PCR with primers 172 -pBlue-F $\left(5^{\prime}\right.$-GGTTCCGATTTAGTGCTTTA-3') and 825-pBu-R (5'-GAAACAGCTATGACCATGAT- $3^{\prime}$ ). These primers were designed to amplify a $1516 \mathrm{bp}$ plasmid fragment, which included a $917 \mathrm{bp}$ inserted PCR product. The pBluescript carrying the C. jejuni htrB gene (named pBlue $h$ trB + ) was isolated from $E$. coli, and then introduced into the $S$. typhimurium htrB mutant by electroporation.

Examination of bacterial growth and morphology. The wildtype, mutant and complemented Salmonella strains were grown on LB agar plates at 30,37 and $42^{\circ} \mathrm{C}$ for $24 \mathrm{~h}$ to $\mathrm{OD}_{600} 0.3$. The culture media were supplemented with appropriate antibiotics. Tetracycline was added to the growth medium used for the S. typhimurium mutant, while ampicillin and tetracycline were added to the growth medium used for the complemented strain. The ability of bacteria to grow at 30,37 and $42{ }^{\circ} \mathrm{C}$ was observed. A Gram stain was performed and the morphology was observed under a light microscope.

Examination of bacterial sensitivity to acid and osmotic stresses. To test for acid sensitivity, the wild-type, mutant and complemented Salmonella strains $\left(\mathrm{OD}_{600} 0.3\right)$ were grown at $30^{\circ} \mathrm{C}$ in $0.1 \%(\mathrm{w} / \mathrm{v})$ peptone water, $\mathrm{pH} 2.5-7.0$, for $24 \mathrm{~h}$. After incubation, cell density was measured at $\mathrm{OD}_{600}$, and an equal volume of culture medium was distributed on LB agar plates. All culture media were supplemented with appropriate antibiotics as described above. The plates were incubated at $30^{\circ} \mathrm{C}$ for another $24 \mathrm{~h}$. To test for osmotic sensitivity, the bacteria were grown as described above, except that $0.1 \%$ peptone water $(\mathrm{pH} 7.0)$ was supplemented with $\mathrm{NaCl}(1-10 \%, \mathrm{w} / \mathrm{v})$.

Examination of bacterial sensitivity to bile stress. To test for bile sensitivity, the wild-type, mutant and complemented Salmonella strains $\left(\mathrm{OD}_{600} 0.3\right)$ were grown on $\mathrm{LB}$ agar plates containing sodium deoxycholate (DOC; 2, 4, 6, 8 and 10\%). The culture media were supplemented with appropriate antibiotics as described above. The plates were incubated at $30^{\circ} \mathrm{C}$ for $24 \mathrm{~h}$.

Treatment of $C$. jejuni with stress environments, and RNA preparation. Prior to the treatment of $C$. jejuni with stress environments, the ability of $C$. jejuni HB 93-13 to grow in brucella broths under heat, acid, osmotic, oxidative or bile stresses was examined. A growth temperature of $44^{\circ} \mathrm{C}$ was selected as heat stress, since $C$. jejuni was able to grow at $43^{\circ} \mathrm{C}$ but not at $45^{\circ} \mathrm{C}$. pH 5.5 was selected as acid stress, since $C$. jejuni showed normal growth at $\mathrm{pH}$ 6.0, inhibited growth at $\mathrm{pH} 5.5$, and no growth at $\mathrm{pH}$ 5.0. A $\mathrm{NaCl}$ concentration of $1.5 \%$ was selected as osmotic stress, since the bacteria showed normal growth at $1 \% \mathrm{NaCl}$, inhibited growth at $1.5 \% \mathrm{NaCl}$, and no growth at $2 \% \mathrm{NaCl}$. As C. jejuni was unable to grow in normal atmospheric conditions, these were used for the oxi-

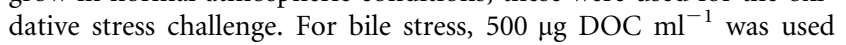
(Lin et al., 2005).

C. jejuni HB 93-13 was grown in $30 \mathrm{ml}$ brucella broth with gentle shaking under microaerobic conditions at $37^{\circ} \mathrm{C}$ for $19 \mathrm{~h}$, and $100 \mu \mathrm{l}$ bacterial culture was aliquoted into six bottles of brucella broth $(30 \mathrm{ml})$, and incubated for another $19 \mathrm{~h}$. After incubation, $1 \mathrm{ml}$ 
brucella broth, which had been supplemented with concentrated $\mathrm{HCl}$, $\mathrm{NaCl}$ or DOC, and pre-warmed at $37^{\circ} \mathrm{C}$, was added to the culture bottles to obtain a final $\mathrm{pH}$ of 5.5 (acid stress), a $\mathrm{NaCl}$ concentration of $1.5 \%$ (osmotic stress), and a DOC concentration of $500 \mu \mathrm{g} \mathrm{ml}^{-1}$ (bile stress). The fourth culture bottle, with $1 \mathrm{ml}$ pre-warmed brucella broth added, was used as the calibrator (normal $h t r B$ expression level). The fifth culture bottle was immediately moved to the $44^{\circ} \mathrm{C}$ incubator (heat stress). Incubation was performed at $37^{\circ} \mathrm{C}$, except for the fifth culture bottle, with gentle shaking under microaerobic conditions. The bacteria from the sixth culture bottle were poured onto culture plates, and incubated at $37^{\circ} \mathrm{C}$ with gentle shaking under normal atmospheric conditions (oxidative stress). Culture samples were collected after incubation for 15 and $30 \mathrm{~min}$, and transferred directly into a $1 / 10$ volume of cold $10 \times$ stop solution [5\% (v/v) phenol in $100 \%$ ethanol] to halt transcription and RNA degradation. RNA samples were isolated using the RNAgents Total RNA Isolation system (Promega), and DNA decontamination was performed using the TURBO DNA-free kit (Ambion).

Quantitative real-time RT-PCR. Primers used for cDNA synthesis were as follows. The primers q-htrB-R ( $5^{\prime}$-TTGAGTGTATTGAGGAAAAC-3'), q-16S rRNA-R (5'-GTATTCTTGGTGATATCTAC-3'; accession no. AL111168), q-luxS-R (5'-ATAAATCCTGCGAATAAATG-3'; accession no. AL111168) and q-rpoA-R (5'-ATTTGTCCATCAGTTGTTAC-3'; accession no. AL111168) were used for synthesis of cDNA for the $h t r B, 16 \mathrm{~S}$ rRNA, luxS and rpoA genes, respectively.

cDNA synthesis was performed using the ImProm-II reverse transcriptase (Promega). One microgram of RNA and $50 \mathrm{ng}$ antisense primer in a total volume of $5 \mu \mathrm{l}$ were heated at $70{ }^{\circ} \mathrm{C}$ for $5 \mathrm{~min}$, and immediately chilled on ice for at least $5 \mathrm{~min}$. The master mix was prepared in a total volume of $15 \mu \mathrm{l}$, which consisted of $5 \mu \mathrm{l}$ RNase-free water, $4 \mu \mathrm{l} 5 \times$ ImProm-II reaction buffer, $2 \mu \mathrm{lgCl}_{2}(25 \mathrm{mM}), 1 \mu \mathrm{l}$ dNTP mix (10 mM each dNTP), $2 \mu$ recombinant RNasin ribonuclease inhibitor $\left(5 \mathrm{U}^{-1}\right)$, and $1 \mu \mathrm{l}$ Improm-II reverse transcriptase ( $1 \mu \mathrm{l}$ per reaction). The master mix was dispensed into the reaction tube containing the mixture of heated RNA and primer. The tube was gently mixed, followed by incubation at $25^{\circ} \mathrm{C}$ for $5 \mathrm{~min}, 42^{\circ} \mathrm{C}$ for $60 \mathrm{~min}$, and $70^{\circ} \mathrm{C}$ for $15 \mathrm{~min}$. Reverse transcriptase was substituted by RNase-free water for the negative control. After cDNA synthesis, $10 \mu \mathrm{l}$ RNase A solution $\left(20 \mu \mathrm{g} \mathrm{ml}^{-1}\right)$ was added to the reaction mixture, incubated at $37^{\circ} \mathrm{C}$ for $20 \mathrm{~min}$, and $220 \mu \mathrm{l}$ water was added. For each gene, a dilution series of newly synthesized cDNA was made and included in a quantitative PCR to examine the efficiency of PCR.

Primers used for PCR were as follows. The primers q-htrB-F ( $5^{\prime}$ TTATGCCTGATTGTATCTTG- $3^{\prime}$ ) and q-htrB-R, as described above, were used to amplify a $125 \mathrm{bp}$ fragment of the $h \operatorname{tr} B$ gene-specific cDNA. The primers q-16S rRNA-F (5'-GTCTCTTGTGAAATCTAATG-3', accession no. CJ11168X3) and q-16S rRNA-R, as described above, were used to amplify a $123 \mathrm{bp}$ fragment of $16 \mathrm{~S}$ rRNA genespecific cDNA. The primers q-luxS-F (5'-AAGTTATGAAAACACCTAAG-3', accession no. CJ11168X4) and q-luxS-R, as described above, were used to amplify a $124 \mathrm{bp}$ fragment of $\operatorname{luxS}$ gene-specific cDNA. The primers q-rpoA-F (5'-GCTTTAGATGCTTTCTTTAC-3' ${ }^{\prime}$, accession no. CJ11168X6) and q-rpoA-R, as described above, were used to amplify a $119 \mathrm{bp}$ fragment of the rpoA gene-specific cDNA.

A quantitative PCR was performed on the MyiQ PCR detection system (Bio-Rad) using iQ SYBR Green Supermix (Bio-Rad), according to the manufacturer's instructions. The PCR reaction was performed in a total volume of $25 \mu \mathrm{l}$, which contained $12.5 \mu \mathrm{l}$ iQ SYBR Green Supermix and $12.5 \mu \mathrm{l}$ master mix, consisting of $1 \mu \mathrm{l}$ forward primer $\left(50 \mathrm{ng} \mu \mathrm{l}^{-1}\right), 1 \mu \mathrm{l}$ reverse primer $\left(50 \mathrm{ng} \mu \mathrm{l}^{-1}\right), 3 \mu \mathrm{l}$ diluted cDNA, and $7.5 \mu \mathrm{l}$ water. Each PCR was performed in duplicate. The same PCR samples that showed variant values of the cycle threshold $\left(\mathrm{C}_{\mathrm{T}}\right)$ of more than 1 were repeated. PCR conditions were as follows: cycle $1(\times 1)$, $95^{\circ} \mathrm{C}$ for $5 \mathrm{~min}$; cycle $2(\times 35), 95^{\circ} \mathrm{C}$ for $30 \mathrm{~s}, 55$ or $60^{\circ} \mathrm{C}$ for $30 \mathrm{~s}$ $\left(55^{\circ} \mathrm{C}\right.$ for $l u x S ; 60^{\circ} \mathrm{C}$ for $h \operatorname{tr} B, 16 \mathrm{~S}$ rRNA gene and $\left.r p o A\right), 72^{\circ} \mathrm{C}$ for $30 \mathrm{~s}$; cycle $3(\times 100), 95^{\circ} \mathrm{C}$ for $10 \mathrm{~s}$ (decrease setpoint temperature after cycle 2 by $0.5^{\circ} \mathrm{C}$, enabling melt-curve data collection and analysis). Each specific amplicon was verified by the presence of both a single melting-temperature peak and a single band of expected size on a $3 \%$ agarose gel after electrophoresis. $\mathrm{C}_{\mathrm{T}}$ values were determined with the MyiQ software (Bio-Rad). The relative changes ( $x$-fold) in gene expression between the induced and calibrator samples were calculated using the $2^{-\Delta \Delta C T}$ method, as described by Livak and Schmittgen (2001). The 16S rRNA, rpoA and/or luxS genes were used as the internal controls. A relative expression value of more than twofold was considered as significant up- or down-regulation.

Construction of the C. jejuni htrB mutant. A pBluescript plasmid carrying the mutated $h t r B$ gene of $C$. jejuni HB 93-13 was constructed. Firstly, a $646 \mathrm{bp}$ DNA fragment containing the partial $w a a C$ and $h t r B$ genes of C. jejuni HB 93-13 (nt 140-785; accession no. AY297047) was amplified by the $p f u$-PCR with primers EcoRIwaaC-F1 (5'-ATAGGAATTCATAGCGGTCCAACACA- $\left.3^{\prime}\right)$ and BamHI-htrB-R1 (5'-AATCGGATCCTATTTAGCCGCATAAGC-3'). The PCR product was cloned into pBluescript in the forward direction via the EcoRI and BamHI sites. The resultant construct was subsequently introduced into E. coli $\mathrm{DH} 5 \alpha$ by electroporation. A positive clone was selected on LB agar supplemented with ampicillin, $\mathrm{X}-\mathrm{Gal}$ and IPTG, according to the blue and white phenotypes. This procedure identified the pBluescript carrying the partial waaC and $h$ trB genes (named pBluA). Secondly, pfu-PCR with primers BamHI-htrB-F2 (5'-TTACGGATCCAGACTGCGTAGAAAACGA$\left.3^{\prime}\right)$ and XbaI-wlaNC-R2 (5'-CCTTTCTAGAGATTTTTACGGCTAAGTG-3') was used to amplify a 678 bp DNA fragment containing the partial $h t r B$ and wlaNC genes (nt 934-1611; accession no. AY297047). This PCR product was cloned into pBluA in the forward orientation via the BamHI and $\mathrm{XbaI}$ sites. Positive clones were identified by colony hybridization using the second PCR product, labelled with DIG using the DIG labelling kit (Roche), as a probe. The colony-DNA probe hybridization was performed at $65^{\circ} \mathrm{C}$ overnight, and detection was performed using the alkaline phosphateconjugated anti-DIG antibody and the nitro-blue tetrazolium chloride/5-bromo-4-chloro-3'-indolyphosphate p-toluidine salt (NBT/ BCIP) substrate, as described in the user's guide handbook (Roche). Positive clones carrying the $h t r B$ gene with a 150 bp (nt 785-934) deletion were named pBluB. A 1494 bp kanamycin resistance cassette $(\mathrm{Km})$ was cloned into pBluB using the BamHI site. This resulted in a construct containing part of the $h t r B$ gene interrupted by the $\mathrm{Km}$ (named $\mathrm{pBluC}$ ), in which the $\mathrm{Km}$ was flanked by a $646 \mathrm{bp}$ upstream and $678 \mathrm{bp}$ downstream DNA fragments. The pBluC carrying the $\mathrm{Km}$ in the same direction as the $h t r B$ gene was named pBluCF, while the construct carrying the $\mathrm{Km}$ in the opposite direction to the $h \operatorname{tr} B$ gene was designated pBluCR. Finally, these constructed plasmids were confirmed by sequencing using the ABI sequencing mix V3.1 (ABI), according to the manufacturer's instructions.

Natural transformation and electroporation were used to introduce each recombinant plasmid (pBluCF and pBluCR) into C. jejuni strains HB 93-13, O:4, O:41, O:36, 81116, 11168, ATCC 43446 and $\mathrm{OH}$ 4382. pBluescript plasmids carrying the $\mathrm{Km}$ within the wlaVA gene (pBlu11KR) or the waaF gene (pBlu13KF) were used as the positive controls. pBluescript alone was used as the negative control. Transformants were screened on $5 \%$ blood agar plates supplemented with kanamycin $\left(15 \mu \mathrm{g} \mathrm{ml}^{-1}\right)$. Culture media were incubated under microaerobic conditions at 30,37 and $42{ }^{\circ} \mathrm{C}$ for 5 days. 


\section{RESULTS AND DISCUSSION}

\section{Characteristics of the C. jejuni htrB gene}

The $h t r B$ homologue of C. jejuni HB 93-13 is located in the wlaII-LOS synthesis gene cluster. DNA sequence analysis of the C. jejuni htrB gene showed an ORF of 888 bp, starting with a methionine when translated. Under microaerobic conditions, the $h t r B$ gene and the other LOS synthesis genes were transcribed as part of several operons using multiple transcriptional start sites with promoters upstream of the start codons of the Cj1132c, waaC, cgtA, cgtB, cstII, wlaQA and waaF genes (V. Phongsisay, unpublished data). Multiple sequence alignments showed that the C. jejuni HB 93-13 HtrB protein was similar to E. coli HtrB (20\%; accession no. NC_004431), S. typhimurium HtrB (20\%; accession no. NC_003197) and H. influenzae HtrB (20\%; accession no. NC_000907) proteins. Among other bacteria, S. typhimurium $\mathrm{HtrB}$ showed $78 \%$ similarity to E. coli $\mathrm{HtrB}$ and $54 \%$ similarity to $H$. influenzae $H$ trB. These results showed that the S. typhimurium, E. coli and H. influenzae HtrB proteins were more closely related to each other than to $C$. jejuni HtrB protein. In S. typhimurium, mutation of the $h t r B$ gene, which encodes an acyltransferase enzyme involved in lipid A synthesis, results in pleiotropic effects in both the pathology and physiology of $S$. typhimurium. These effects include morphological changes from short to filamentous rods, hyperflagellation, inability to grow at high temperatures, increased bile resistance, and reduced virulence (Jones et al., 1997; Sunshine et al., 1997). In this study, the S. typhimurium $h t r B$ mutant was used as a model for studying the pleiotropic effects resulting from expression of the C. jejuni htrB gene. The S. typhimurium htrB mutant was complemented with the htrB gene from $C$. jejuni HB 93-13. The wild-type, mutant and complemented Salmonella strains were characterized.

\section{Role of the C. jejuni htrB gene in S. typhimurium morphology}

To examine whether expression of the C. jejuni htrB gene affected the morphology of the S. typhimurium htrB mutant, the wild-type, mutant and complemented Salmonella strains were grown on LB agar plates at 30, 37 and $42{ }^{\circ} \mathrm{C}$ for $24 \mathrm{~h}$. The culture media were supplemented with appropriate antibiotics. A Gram stain was performed and the morphology was observed under a light microscope. The morphology of the complemented and wild-type strains was similar, showing Gram-negative short rods at 30,37 and $42^{\circ} \mathrm{C}$, while the morphology of the mutant displayed Gram-negative, filamentous, bulging, short rods at all temperatures tested (Fig. 1a). These results show that the C. jejuni htrBgene could restore the wild-type morphology of the S. typhimurium htrB mutant, and hence its expression affected the bacterial morphology.

\section{Role of the C. jejuni htrB gene in growth of S. typhimurium at high temperature}

To examine whether expression of the C. jejuni htrB gene affected the capacity of bacteria to grow at high temperature, the wild-type, mutant and complemented Salmonella strains were grown on LB agar plates, as previously described. The results showed that the $C$. jejuni htrB gene could restore the ability of the S. typhimurium htrB mutant to grow at high temperatures, as the complemented and wild-type strains grew normally at 30,37 and $42^{\circ} \mathrm{C}$, while the mutant was temperature-sensitive and showed inhibited growth at 37 and $42^{\circ} \mathrm{C}$ (Fig. 1b). This shows that the C. jejuni htrB gene is essential for the $S$. typhimurium $h t r B$ mutant to grow properly at high temperature. A previous study has shown that the S. typhimurium htrB mutant is unable to grow at $37^{\circ} \mathrm{C}$ (Sunshine et al., 1997), while in this study, this bacterial strain showed inhibited growth at $37^{\circ} \mathrm{C}$ (Fig. 1b). These inconsistent results may be explained by a loss of temperature sensitivity of the $S$. typhimurium htrB mutant after a few passages at $30{ }^{\circ} \mathrm{C}$, which has also been observed for the $H$. influenzae htrB mutant (Lee et al., 1995).

\section{Role of the C. jejuni htrB gene in acid sensitivity of $S$. typhimurium}

To examine whether expression of the C. jejuni htrB gene affected acid sensitivity, the wild-type, mutant and complemented Salmonella strains were grown at $30{ }^{\circ} \mathrm{C}$ in $0.1 \%(\mathrm{w} / \mathrm{v})$ peptone water $(\mathrm{pH} 2.5-7.0)$ for $24 \mathrm{~h}$. After incubation, the cell density was measured at $\mathrm{OD}_{600}$, and an equal volume of culture medium was distributed on LB agar plates. All culture media were supplemented with appropriate antibiotics, as described above. The plates were incubated at $30{ }^{\circ} \mathrm{C}$ for another $24 \mathrm{~h}$. The results showed that the mutant strain exhibited less growth on LB agar plates compared to the wild-type, and the complemented strain showed growth intermediate between those of the wild-type and mutant strains at lower $\mathrm{pH}$ (Fig. 1c, selected results of bacterial growth on LB plates). Therefore, expression of the C. jejuni htrB gene contributed to the acid tolerance of the S. typhimurium htrB mutant.

\section{Role of the C. jejuni htrB gene in high osmotic sensitivity of $S$. typhimurium}

To examine whether expression of the C. jejuni htrB gene affected osmotic sensitivity, the wild-type, mutant and complemented Salmonella strains were grown as described above in an acid-sensitivity assay, except that $0.1 \%$ peptone water ( $\mathrm{pH} 7.0$ ) was supplemented with $\mathrm{NaCl}(1-10 \%)$. The complemented and wild-type strains exhibited similar growth, while the mutant showed inhibited growth (Fig. 1d, selected result). Therefore, the results showed that expression of the C. jejuni htrB gene contributed to the osmotic resistance of the $S$. typhimurium htrB mutant.

\section{Role of the C. jejuni htrB gene in bile sensitivity of $S$. typhimurium}

To examine whether expression of the C. jejuni htrB gene affected bile sensitivity, the wild-type, mutant and complemented Salmonella strains were grown on LB agar plates supplemented with 2, 4, 6, 8 and $10 \%$ DOC. The results 

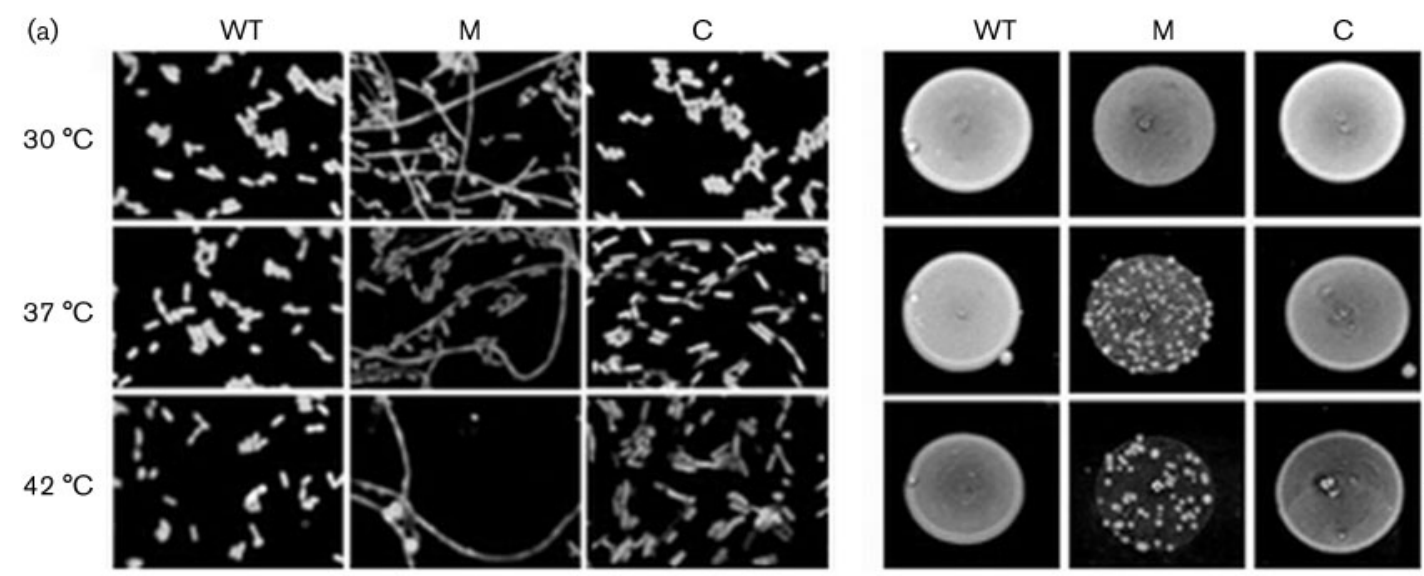

(b)
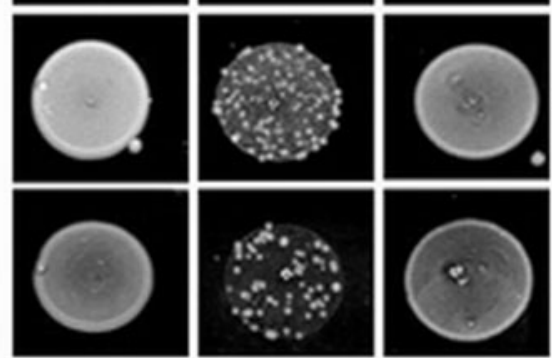

$30^{\circ} \mathrm{C}$
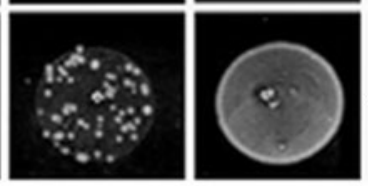

$42{ }^{\circ} \mathrm{C}$

(c)
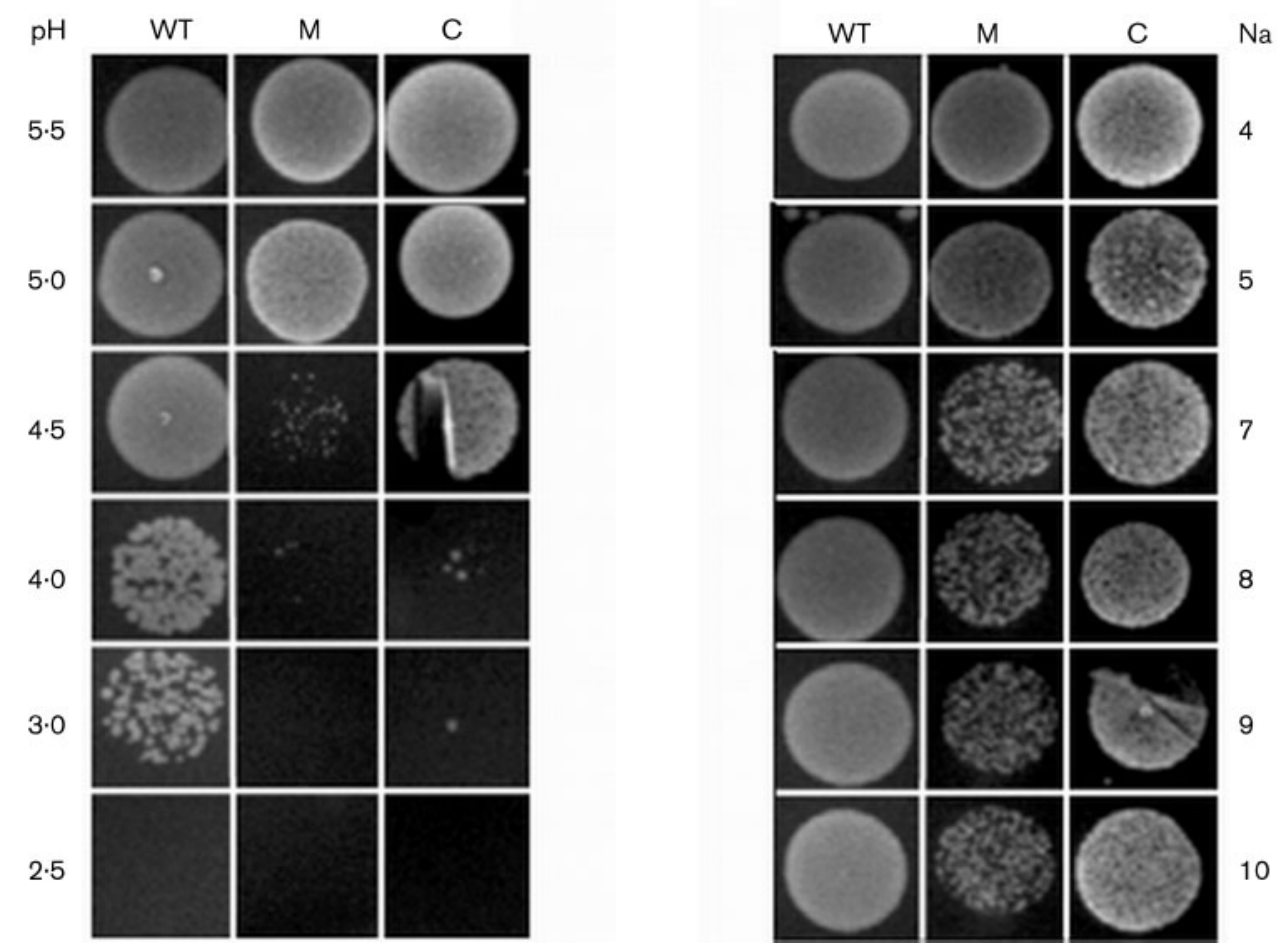

(d)

Fig. 1. Complementation experiments. WT, wild-type S. typhimurium strain SL1344; M, S. typhimurium htrB mutant; C, S. typhimurium htrB mutant carrying the functional htrB gene from C. jejuni $\mathrm{HB}$ 93-13; $\mathrm{Na}, \mathrm{NaCl}$ concentration (\%). (a) Morphology at different temperatures; (b) ability of bacteria to grow at high temperatures; (c) ability of bacteria to grow in high acidity; (d) ability of bacteria to grow in high osmolality.

showed that the C. jejuni htrB gene could not complement the bile sensitivity of the $S$. typhimurium htrB mutant, as the mutant and complemented strains were able to grow in all DOC concentrations tested, while the wild-type strain was able to grow in DOC up to $8 \%$. Similarly, a bile-resistant phenotype of the S. typhimurium htrB mutant has also been observed by Sunshine et al. (1997). However, the study of bile sensitivity in other bacteria has shown inconsistent results. The $H$. influenzae htrB mutant is more bile sensitive than the wild-type strain (Lee et al., 1995), while the E. coli $h t r B$ mutant is more bile resistant than the wild-type strain (Karow \& Georgopoulos, 1992; Sunshine et al., 1997). Since expression of the $C$. jejuni htrB gene did not affect the bile sensitivity of the S. typhimurium htrB mutant, the $C$. jejuni $h t r B$ gene might not have a role in bile sensitivity in $C$. jejuni.

\section{Expression of the htrB gene in C. jejuni under stress environments}

To examine whether stress environments, including heat, acid, osmotic, oxidative and bile stresses, affected expression of the htrB gene in C. jejuni, quantitative real-time RT-PCR was performed. Before the quantitative data were accepted, we required three criteria. First, no PCR product should be 
detected from the negative control without reverse transcriptase, confirming the lack of DNA contamination in the RNA sample. Second, PCR efficiency for each gene should be $\geqslant 80 \%$. This ensured that low amounts of PCR product were due to low expression levels of the genes of interest, and not the result of low PCR efficiency. Third, only one peak for each gene analysed should be observed in the melting curve, confirming the lack of non-specific PCR product. In this study, the $r p o A$ gene encoding the alpha subunit of RNA polymerase, and the $16 \mathrm{~S}$ rRNA gene (Parkhill et al., 2000) were used as internal negative controls, and it was expected that their expression should not be affected by a change of environment. The luxS or Cj1198 gene (Parkhill et al., 2000), which produces the autoinducer2 involved in quorum sensing (Elvers \& Park, 2002), was used as an internal positive control, and its expression should be affected by a change of environment. The results showed that there was no ideal and universal internal positive/negative control. For example, after $C$. jejuni was exposed to stress environments for $15 \mathrm{~min}$, expression of the luxS gene was not affected by heat and bile stresses but it was affected by other stresses. Expression of the 16S rRNA gene showed less variation under osmotic and oxidative stresses, but it showed higher variation under other environments when compared with that of other genes (Table 1). As a result, for each environment, expression of the control gene that showed lowest variation was selected as the internal control. Therefore, at $15 \mathrm{~min}$, the $r p o A$ gene was selected as the internal control for studying $h t r B$ expression under acid stress, the luxS gene was used as the control under heat and bile stresses, and the 16S rRNA gene as the control under oxidative and osmotic stresses. At $30 \mathrm{~min}$, the $\operatorname{luxS}$ and rpoA genes were selected as the control genes under acid and heat stresses, respectively. The 16S rRNA gene was selected as the control gene under oxidative, bile and osmotic stresses. After the expression level of the $h r t B$ gene was subtracted from that of the internal control, it was found that, after $C$. jejuni was exposed to each artificial environment for $15 \mathrm{~min}$, expression of the $h t r B$ gene was highly upregulated under acid stress, moderately upregulated under heat and oxidative stresses, slightly upregulated under osmotic stress, and did not change under bile stress. After $15 \mathrm{~min}$ of exposure, hrtB expression gradually decreased with time to reach or approach the baseline level at $30 \mathrm{~min}$. At this time point, expression of the $h t r B$ gene was moderately upregulated under acid stress, slightly upregulated under oxidative stress, and did not change under bile, osmotic or heat stresses (Table 1). These results show that the C. jejuni htrB gene is involved in regulating cell responses to various environmental changes. This is consistent with our previous results showing that the C. jejuni htrB gene is essential for the S. typhimurium htrB mutant to grow at high temperatures, acidity and osmolality.

\section{Table 1. Expression of the C. jejuni htrB gene under stress environments}

$\mathrm{ND}$, Not determined. Bold type signifies a $\mathrm{C}_{\mathrm{T}}$ value of the internal control genes that did not change or was slightly affected by change of environment; these genes were selected as the internal controls for particular environments. For example, at 15 min, the rpoA gene was used as the control gene under acid stress, as its expression $\left(\mathrm{C}_{\mathrm{T}}\right)$ was not affected by acid stress (24.00 versus 24.24 under normal conditions).

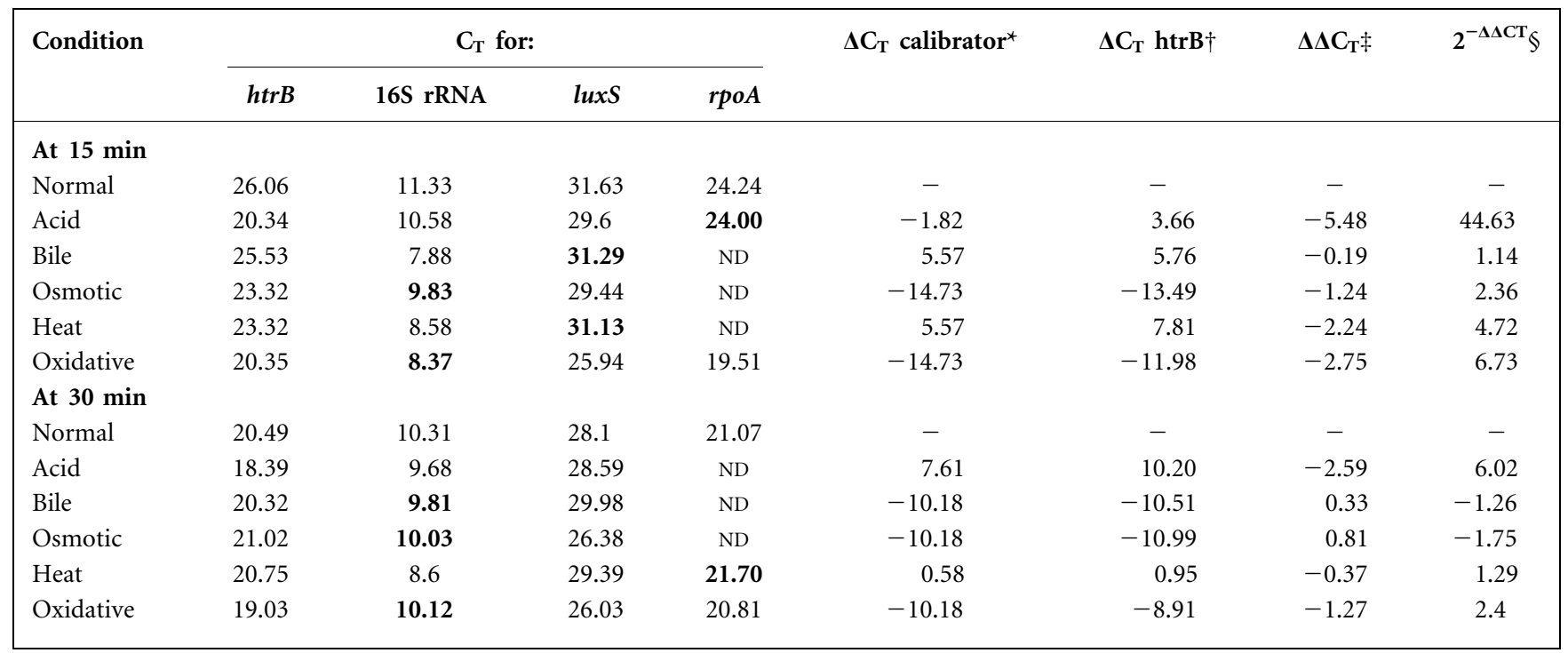

${ }^{\star}$ The $\Delta \mathrm{C}_{\mathrm{T}}$ calibrator was calculated by subtracting the $\mathrm{C}_{\mathrm{T}}$ value of the control gene under normal conditions from that of the $h t r B$ gene under normal conditions.

$\dagger \Delta \mathrm{C}_{\mathrm{T}}$ htrB was calculated by subtracting the $\mathrm{C}_{\mathrm{T}}$ value of the control gene under stress from that of $h$ trB gene under the same stress. $\ddagger \Delta \Delta \mathrm{C}_{\mathrm{T}}$ was calculated by subtracting the value of the $\Delta \mathrm{C}_{\mathrm{T}}$ calibrator from the value of $\Delta \mathrm{C}_{\mathrm{T}} \mathrm{htrB}$.

$\$ 2^{-\Delta \Delta \mathrm{CT}}>2$, gene expression was upregulated; $2^{-\Delta \Delta \mathrm{CT}}<-2$, gene expression was down-regulated; $-2 \geqslant 2^{-\Delta \Delta \mathrm{CT}} \leqslant 2$, gene expression was not affected by change of environment. 
The results of the real-time RT-PCR experiments showed that expression of the C. jejuni htrB gene was upregulated under harsh environments, including heat stress. In contrast, an earlier study using Northern blot analysis has shown that expression of the E. coli htrB gene is not affected by heat-shock (Karow \& Georgopoulos, 1991). It is proposed that the E. coli htrB gene is a member of a new class of genes whose products are required for growth at high temperature, but are not heat-shock genes (Karow \& Georgopoulos, 1992). Similarly, using microarray analysis, expression of the $h t r B$ gene of C. jejuni NCTC 11168 is not significantly up- or down-regulated after the growth temperature is shifted from 37 to $42{ }^{\circ} \mathrm{C}$ (Stintzi, 2003). This inconsistent result might be due to the sensitivity of the methods used. From our results and the fact that real-time RT-PCR is the most sensitive method for differential gene expression, we believe that expression of the $C$. jejuni htrB gene is affected by heat shock.

\section{Effect of modulation of lipid A acylation in C. jejuni}

To examine the effect of modification of lipid A acylation in C. jejuni, the acyltransferase-encoding htrB homologous gene was inactivated using mutagenesis. Firstly, two recombinant pBluescript plasmids were constructed. The first construct carried the Km within the $h \operatorname{trB}$ gene in the same orientation (pBluCF). The second construct carried the $\mathrm{Km}$ in the reverse orientation to the $h t r B$ gene (pBluCR). Secondly, natural transformation and electro-transformation were used to transform various $C$. jejuni strains with these constructs. Plasmids carrying a Km within the wlaVA gene (pBlu11KR) and within the waaF gene (pBlu13KF) were used as positive controls. The pBluescript without an insert was used as a negative control. Transformants were screened on a selective medium that was supplemented with a low concentration of kanamycin $\left(15 \mu \mathrm{g} \mathrm{ml}^{-1}\right)$, since the $H$. influenzae htrB mutant has been shown elsewhere to be hypersensitive to kanamycin (Lee et al., 1995). The culture media were incubated at 30,37 and $42^{\circ} \mathrm{C}$ for 5 days, since an earlier study has shown that the E. coli htrB mutants cannot initially grow on rich media at temperatures above $33^{\circ} \mathrm{C}$ (Karow et al., 1991). As expected, a number of $C$. jejuni waaF and wlaVA mutants were obtained from the positive controls, and no transformants were recovered from the negative control. This shows that the possibility that different restriction-modification systems between $C$. jejuni and E. coli are a barrier for interstrain plasmid transfer can be ruled out. No transformants carrying the mutated $h t r B$ gene as a result of homologous recombination via a double crossover event were recovered on the selective medium. However, a few transformants carrying both an intact and a mutated $h \mathrm{tr} B$ gene resulting from a single crossover were observed. After several passages of these transformants, and after transformant-derived genomic DNA was introduced into the parental C. jejuni strain HB 93-13, individual progeny still carried both mutated and intact $h t r B$ genes (data not shown). These results indicate that the $h \operatorname{tr} B$ gene is essential for $C$. jejuni survival, and hence gene deletion in $C$. jejuni causes loss of cell viability.

A previous study has shown that the plasmid transformation frequency via homologous recombination directly correlates with the size of the flanking regions (Wassenaar et al., 1993). DNA recombination between the inserts present in suicide vectors and the genome occurs with as little as 200 homologous base pairs being present (Wassenaar et al., 1993). pBluCF and pBluCR carried the Km flanked by a $646 \mathrm{bp}$ upstream region consisting of the partial waaC and $h t r B$ genes, and a 678 bp downstream region consisting of the partial $h t r B$ and wlaNC genes. Therefore, the sizes of these flanking regions should have been sufficient to initiate homologous recombination in C. jejuni.

The possible explanations as to why the $h t r B$ gene could be mutated in other bacteria but not in $C$. jejuni are as follows. First, unlike most other bacteria, $C$. jejuni is a fragile enteric bacterium. For example, we found that growth of $C$. jejuni was not observed in brucella broth with $\mathrm{NaCl}>1.5 \%$, DOC $>2 \%$ or $\mathrm{pH}<5.5$. In addition, $C$. jejuni is hypersensitive to normal atmospheric conditions. In contrast, the growth of S. typhimurium was still observed in medium consisting of $10 \% \mathrm{NaCl}, 10 \% \mathrm{DOC}$ or $\mathrm{pH} 3.0$, and it was able to grow under normal atmospheric conditions. Second, the results of the complementation and gene expression experiments presented here indicate that the C. jejuni htrB gene is involved in morphology (cell wall formation), and is essential for growth under stress environments, including acid, heat, osmotic and oxidative stresses. Third, accomplishment of inactivation of the $h t r B$ genes might depend on mutagenesis-based techniques. In this study, deletion mutation was employed to inactivate the $h t r B$ gene in $C$. jejuni (see Methods). Several attempts were made without success. In contrast, insertional mutagenesis of the $h t r B$ genes using transposon-based techniques is successful in $S$. typhimurium (Sunshine et al., 1997), E. coli (Karow et al., 1991) and H. influenzae (Lee et al., 1995). Similarly, deletion mutation of the waaC gene, which is located upstream of the $h t r B$ gene, results in loss of viability of C. jejuni strain 81116 (B. N. Fry, unpublished data), while insertion mutation of the waaC homologous gene in C. jejuni strain 81-176 is successful (Kanipes et al., 2006). Therefore, deletion mutation of the C. jejuni htrB gene might result in cell wall dysfunction, such as loss of membrane permeability, leading to bacterial cell death.

The role of the C. jejuni htrB gene in lipid A synthesis is controversial. A number of previous studies have proposed that the $C$. jejuni $h$ trB gene encodes a putative acyltransferase involved in lipid A synthesis (Gilbert et al., 2002; Parkhill et al., 2000). Since bile is responsible for digesting fats by disaggregating the lipid bilayer of the cellular membrane, inactivation of the lipid A synthesis gene should increase the bile sensitivity of bacterial cells. Generally, if the $C$. jejuni $h t r B$ gene has a role in lipid A synthesis, its expression should be affected under bile stress. This study indicates that the $h t r B$ gene might not play a role in lipid A synthesis, since its 
expression did not change when C. jejuni was exposed to bile stress. Additionally, it could not complement the bile sensitivity of the S. typhimurium htrB mutant. As the role of the S. typhimurium htrB gene in lipid A synthesis could be demonstrated by MS of the crude lipid A fraction, this technology could also be used to analyse the $C$. jejuni $h t r B$ gene and its role in lipid A synthesis.

In conclusion, this study shows that: (i) expression of the $C$. jejuni $h t r B$ gene is essential for the response of $S$. typhimurium to stress environments; (ii) the C. jejuni htrB gene is involved in regulating cell responses to environmental changes; and (iii) it is likely that the $h \operatorname{trB}$ gene is essential for $C$. jejuni survival.

\section{REFERENCES}

Aspinall, G. O., McDonald, A. G., Pang, H., Kurjanczyk, L. A. \& Penner, J. L. (1994). Lipopolysaccharides of Campylobacter jejuni serotype O:19: structures of core oligosaccharide regions from the serostrain and two bacterial isolates from patients with the GuillainBarré syndrome. Biochemistry 33, 241-249.

Ausubel, F. M., Brent, R., Kingston, R. E., Moore, D. D., Seidman, J. G., Smith, J. A. \& Struhl, K. (1995). Current Protocols in Molecular Biology. New York: Wiley.

Coker, A. O., Isokpehi, R. D., Thomas, B. N., Amisu, K. O. \& Obi, C. L. (2002). Human campylobacteriosis in developing countries. Emerg Infect Dis 8, 237-244.

Elvers, K. T. \& Park, S. F. (2002). Quorum sensing in Campylobacter jejuni: detection of a luxS encoded signalling molecule. Microbiology 148, 1475-1481.

Fry, B. N., Feng, S., Chen, Y. Y., Newell, D. G., Coloe, P. J. \& Korolik, V. (2000). The galE gene of Campylobacter jejuni is involved in lipopolysaccharide synthesis and virulence. Infect Immun 68, 2594-2601.

Gilbert, M., Brisson, J. R., Karwaski, M. F., Michniewicz, J., Cunningham, A. M., Wu, Y., Young, N. M. \& Wakarchuk, W. W. (2000). Biosynthesis of ganglioside mimics in Campylobacter jejuni $\mathrm{OH} 4384$. Identification of the glycosyltransferase genes, enzymatic synthesis of model compounds, and characterization of nanomole amounts by $600-\mathrm{mhz}{ }^{1} \mathrm{H}$ and ${ }^{13} \mathrm{C}$ NMR analysis. J Biol Chem 275, 3896-3906.

Gilbert, M., Karwaski, M. F., Bernatchez, S., Young, N. M., Taboada, E., Michniewicz, J., Cunningham, A. M. \& Wakarchuk, W. W. (2002). The genetic bases for the variation in the lipooligosaccharide of the mucosal pathogen, Campylobacter jejuni. Biosynthesis of sialylated ganglioside mimics in the core oligosaccharide. J Biol Chem 277, 327-337.

Ho, T. W., Mishu, B., Li, C. Y., Gao, C. Y., Cornblath, D. R., Griffin, J. W., Asbury, A. K., Blaser, M. J. \& McKhann, G. M. (1995). GuillainBarré syndrome in northern China. Relationship to Campylobacter jejuni infection and anti-glycolipid antibodies. Brain 118, 597-605.

Jones, B. D., Nichols, W. A., Gibson, B. W., Sunshine, M. G. \& Apicella, M. A. (1997). Study of the role of the $h t r B$ gene in Salmonella typhimurium virulence. Infect Immun 65, 4778-4783.

Kanipes, M. I., Papp-Szabo, E., Guerry, P. \& Monteiro, M. A. (2006). Mutation of waaC, encoding heptosyltransferase I in Campylobacter jejuni 81-176, affects the structure of both lipooligosaccharide and capsular carbohydrate. J Bacteriol 188, 3273-3279.
Karow, M. \& Georgopoulos, C. (1991). Sequencing, mutational analysis, and transcriptional regulation of the Escherichia coli htrB gene. Mol Microbiol 5, 2285-2292.

Karow, M. \& Georgopoulos, C. (1992). Isolation and characterization of the Escherichia coli msbB gene, a multicopy suppressor of null mutations in the high-temperature requirement gene htrB. J Bacteriol 174, 702-710.

Karow, M., Fayet, O., Cegielska, A., Ziegelhoffer, T. \& Georgopoulos, C. (1991). Isolation and characterization of the Escherichia coli htrB gene, whose product is essential for bacterial viability above 33 degrees $\mathrm{C}$ in rich media. J Bacteriol 173, 741-750.

Lee, N. G., Sunshine, M. G., Engstrom, J. J., Gibson, B. W. \& Apicella, M. A. (1995). Mutation of the htrB locus of Haemophilus influenzae nontypable strain 2019 is associated with modifications of lipid A and phosphorylation of the lipooligosaccharide. J Biol Chem 270, 27151-27159.

Lin, J., Cagliero, C., Guo, B., Barton, Y. W., Maurel, M. C., Payot, S. \& Zhang, Q. (2005). Bile salts modulate expression of the CmeABC multidrug efflux pump in Campylobacter jejuni. J Bacteriol 187, 7417-7424.

Livak, K. J. \& Schmittgen, T. D. (2001). Analysis of relative gene expression data using real-time quantitative PCR and the 2(-Delta Delta C(T)) method. Methods 25, 402-408.

Monselise, A., Blickstein, D., Ostfeld, I., Segal, R. \& Weinberger, M. (2004). A case of cellulitis complicating Campylobacter jejuni subspecies jejuni bacteremia and review of the literature. Eur J Clin Microbiol Infect Dis 23, 718-721.

Naess, V. \& Hofstad, T. (1984). Chemical composition and biological activity of lipopolysaccharides prepared from type strains of Campylobacter jejuni and Campylobacter coli. Acta Pathol Microbiol Immunol Scand $[B]$ 92, 217-222.

O'Ryan, M., Prado, V. \& Pickering, L. K. (2005). A millennium update on pediatric diarrheal illness in the developing world. Semin Pediatr Infect Dis 16, 125-136.

Palmer, S. R., Gully, P. R., White, J. M., Pearson, A. D., Suckling, W. G., Jones, D. M., Rawes, J. C. \& Penner, J. L. (1983). Waterborne outbreak of Campylobacter gastroenteritis. Lancet $\mathbf{1}$, 287-290.

Parker, C. T., Horn, S. T., Gilbert, M., Miller, W. G., Woodward, D. L. \& Mandrell, R. E. (2005). Comparison of Campylobacter jejuni lipooligosaccharide biosynthesis loci from a variety of sources. J Clin Microbiol 43, 2771-2781.

Parkhill, J., Wren, B. W., Mungall, K., Ketley, J. M., Churcher, C., Basham, D., Chillingworth, T., Davies, R. M., Feltwell, T. \& other authors (2000). The genome sequence of the food-borne pathogen Campylobacter jejuni reveals hypervariable sequences. Nature 403, 665-668.

Ramon Maestre, J., Buezas, V., Sanchez, P., Montero, A. \& Mellado, F. (2001). Bacteremia caused by Campylobacter jejuni in a 22 year old male with autoimmune haemolytic anaemia. Enferm Infecc Microbiol Clin 19, 457-458 (in Spanish).

Sambrook, J. \& Russell, D. W. (2000). Molecular Cloning: a Laboratory Manual, 3rd edn. Cold Spring Harbor, NY: Cold Spring Harbor Laboratory.

Starner, T. D., Swords, W. E., Apicella, M. A. \& McCray, P. B., Jr (2002). Susceptibility of nontypeable Haemophilus influenzae to human beta-defensins is influenced by lipooligosaccharide acylation. Infect Immun 70, 5287-5289.

Stintzi, A. (2003). Gene expression profile of Campylobacter jejuni in response to growth temperature variation. J Bacteriol 185, 2009-2016. 
Sunshine, M. G., Gibson, B. W., Engstrom, J. J., Nichols, W. A., Jones, B. D. \& Apicella, M. A. (1997). Mutation of the $h t r B$ gene in a virulent Salmonella typhimurium strain by intergeneric transduction: strain construction and phenotypic characterization. J Bacteriol 179, 5521-5533.

Swords, W. E., Chance, D. L., Cohn, L. A., Shao, J., Apicella, M. A. \& Smith, A. L. (2002). Acylation of the lipooligosaccharide of Haemophilus influenzae and colonization: an htrB mutation diminishes the colonization of human airway epithelial cells. Infect Immun 70, 4661-4668.

Tong, H. H., Chen, Y., James, M., Van Deusen, J., Welling, D. B. \& DeMaria, T. F. (2001). Expression of cytokine and chemokine genes by human middle ear epithelial cells induced by formalin-killed
Haemophilus influenzae or its lipooligosaccharide $h \operatorname{tr} B$ and $r f a D$ mutants. Infect Immun 69, 3678-3684.

Wassenaar, T. M., Fry, B. N. \& van der Zeijst, B. A. (1993). Genetic manipulation of Campylobacter: evaluation of natural transformation and electro-transformation. Gene 132, 131-135.

Yuki, N., Susuki, K., Koga, M., Nishimoto, Y., Odaka, M., Hirata, K., Taguchi, K., Miyatake, T., Furukawa, K. \& other authors (2004). Carbohydrate mimicry between human ganglioside GM1 and Campylobacter jejuni lipooligosaccharide causes Guillain-Barré syndrome. Proc Natl Acad Sci U S A 101, 11404-11409.

Edited by: P. H. Everest 